NBER WORKING PAPER SERIES

\title{
INTEREST RATE UNCERTAINTY AND SOVEREIGN DEFAULT RISK
}

\author{
Alok Johri \\ Shahed Khan \\ César Sosa-Padilla \\ Working Paper 27639 \\ http://www.nber.org/papers/w27639 \\ NATIONAL BUREAU OF ECONOMIC RESEARCH \\ 1050 Massachusetts Avenue \\ Cambridge, MA 02138 \\ August 2020, Revised August 2022
}

The most up-to-date version of this paper can be found here. We have benefited from comments and suggestions from the editor (Fernando Broner), two anonymous referees, as well as from Manuel Amador, Agustín Benetrix, Marinho Bertanha, Nathan Converse, Ethan Ilzetzki, Hashmat Khan, Juan Carlos Hatchondo, Leonardo Martinez, Enrique Mendoza, Juanpa Nicolini, Ananth Ramanarayanan, Zach Stangebye, Michal Szkup, Martín Uribe, Stephen Williamson, and seminar participants at UBC, Saint's Mary, Western, Queen's, Carleton, Notre Dame, Trinity College Dublin, European University Institute, McMaster, Universidad Nacional de Tucumán, the 2021 AEA Annual Meetings, the 2019 Midwest Macroeconomics Meeting, the 2019 Computing in Economics and Finance Annual Meeting, the 50th Anniversary of the Money, Macro \& Finance Conference, the 10th RCEA MMF Conference, the 2016 and 2017 Society for Economic Dynamics Annual Meetings, and the 2015 Canadian Economic Association Annual Meeting. We also thank Steve Wu for sharing data with us. Research for this project was supported by the Social Science and Humanities Research Council of Canada grant number 435-2016-0708. All remaining errors are ours. The views expressed herein are those of the authors and do not necessarily reflect the views of the National Bureau of Economic Research.

NBER working papers are circulated for discussion and comment purposes. They have not been peer-reviewed or been subject to the review by the NBER Board of Directors that accompanies official NBER publications.

(C) 2020 by Alok Johri, Shahed Khan, and César Sosa-Padilla. All rights reserved. Short sections of text, not to exceed two paragraphs, may be quoted without explicit permission provided that full credit, including $\left({ }^{\circ}\right.$ notice, is given to the source. 
Interest Rate Uncertainty and Sovereign Default Risk

Alok Johri, Shahed Khan, and César Sosa-Padilla

NBER Working Paper No. 27639

August 2020, Revised August 2022

JEL No. E32,E43,F34,F41

\begin{abstract} across nations, as seen in the data.

Alok Johri

Department of Economics

McMaster University

1280 Main Street West

Hamilton, ON CANADA L8S 4M4

johria@mcmaster.ca

Shahed Khan

Department of Economics

University of Western Ontario

1151 Richmond Street N.

London, ON

CANADA

mkhan333@uwo.ca

César Sosa-Padilla

Department of Economics

University of Notre Dame

3060 Jenkins Nanovic Hall

Notre Dame, IN 46556

and NBER

csosapad@nd.edu
\end{abstract}

Empirical studies suggest that fluctuations in the level and volatility of the world interest rate affect sovereign spreads in emerging economies. We incorporate an estimated time-varying process for the world interest rate (with both level and volatility shocks) into a model of sovereign default calibrated to a panel of emerging economies. Time variation in the world interest rate interacts with default incentives in the model and leads to state contingent effects similar to the empirical literature. On average, in response to a rise in the world interest rate the model delivers a 1.4 times increase in the spread. The volatility state has a major impact on this average - the increase in spreads is much larger in high volatility states. Moreover, we show that fluctuations in the world interest rate can generate considerable co-movement in sovereign yields 


\section{Introduction}

The emerging economy business cycle literature has shown that shocks to country spreads play an important role in accounting for domestic business cycles. In addition, a large body of empirical work has traced variation in emerging economy spreads and default risk to both domestic and global factors. ${ }^{1}$ Motivated by this work, the sovereign default literature provides a framework in which time varying default probabilities generate endogenous variation in sovereign yields. ${ }^{2}$ However, this literature has emphasized the role of domestic factors with little attention to the global interlinkages highlighted by the empirical work. ${ }^{3}$ Our paper addresses this gap by focusing on the relationship between uncertainty in the world interest rate and sovereign default risk, while also retaining a role for domestic factors. Our focus on variation in the world interest rate as a global factor is consistent with several studies. For example, González-Rozada and Levy Yeyati (2008) finds that movements in US treasuries as well as in proxies for global risk explain about half of the long run volatility in emerging economy interest rates. ${ }^{4}$

Some recent episodes highlight the importance of the behavior of US interest rates for world debt markets. A notorious example, usually referred to as the "taper tantrum," occurred in May of 2013 when former US Fed chairman Ben Bernanke suggested the possibility of a reduction in future bond purchases by the Fed. This triggered a sharp market adjustment in emerging market economies featuring a reversal in capital flows and a spike in government bond yields. On average, sovereign yields across emerging economies rose by 1\% (Rai and Suchanek, 2014). An example of policy makers' dislike of uncertainty about the world interest rate occurred in 2015, as summarized by the following quotes reported in the Financial

\footnotetext{
${ }^{1}$ See early work in Edwards, 1984, Cantor and Packer, 1996 and Eichengreen and Mody, 2000. For some recent examples of studies that highlight global factors, see Hilscher and Nosbusch (2010), González-Rozada and Levy Yeyati (2008) Akınc1 (2013), and Maltritz (2012).

${ }^{2}$ We use the terms "sovereign" and "government" interchangeably throughout the paper.

${ }^{3}$ Below we discuss a few papers that do highlight the role of global risk aversion.

${ }^{4}$ These findings are re-iterated using a variety of empirical methods and proxies for global risk, different time periods, and different countries in other work. For example, Akıncı (2013) uses a structural VAR on a panel of emerging economies while Maltritz (2012) uses Bayesian model averaging on a panel of European nations and both replace the high yield spreads used by González-Rozada and Levy Yeyati (2008) (as a measure of gloabl risk) with corporate bond spreads captured by BAA bonds. Hilscher and Nosbusch (2010) add VIX as a measure of global uncertainty and find that it is statistically significant in explaining credit default swap (CDS) spreads of Mexico, Turkey, and Korea.
} 
Times (September 9, 2015):

"We think US monetary policymakers have got confused about what to do. The uncertainty has created the turmoil."

Mirza Adityaswara, Sr. Deputy Governor, Central Bank of Indonesia.

"The uncertainty about when the Fed hike will happen is causing more damage than the Fed hike will itself."

Julio Velarde, Governor, Central Bank of Peru.

Motivated both by the empirical evidence on the importance of global factors in the movement of emerging economies' sovereign spreads as well as recent events and policy makers' concerns, we develop an equilibrium model of sovereign default (in the tradition of Eaton and Gersovitz, 1981) to study the relationship between endogenous country spreads and movements in both the level and the volatility of the world interest rate. To do so, we introduce stochastic volatility into the process of the world interest rate (following FernándezVillaverde, Guerrón-Quintana, Rubio-Ramírez and Uribe, 2011) in an otherwise standard quantitative model of long term sovereign debt (as in Hatchondo and Martinez, 2009). We use the model to quantify the role that shocks to the world interest rate play in explaining variation in sovereign spreads and the borrowing levels chosen by the sovereign, as well as the cross-country correlation in borrowing costs induced by the world interest rate process.

Our model implies that the impact of shocks to the world interest rate are highly state contingent and depend on income and existing debt levels, as well as on the state of world interest itself (its level and volatility). We find that on average the spread response is 1.4 times the increase in the world interest rate when volatility and the debt level are held constant at their means. This 'slope' increases to 6.4 when volatility state is high ( 4 standard deviations above mean) and falls to 0.8 when volatility is low ( 4 standard deviations below mean). Not surprisingly, a higher debt level makes the spread response to the world interest rate stronger and below-average debt lowers the response. Interestingly, these 'spread slopes' are in line with the empirical evidence (a spread slope of roughly 1), presented in Foley-Fisher and Guimaraes (2013) and Arora and Cerisola (2001). We also find that debt issuance 
declines when the world interest rate rises and this responsiveness is higher in the high volatility state as compared to the low volatility state.

Since our model can be viewed as a mechanism that transmits shocks in the process for the world interest rate into fluctuations in default probabilities and hence in sovereign spreads, we can use the model to infer how much cross-country co-movement in spreads is generated by this "global factor." We find that when two economies (with income process as correlated as in the data) face a constant world interest rate, their sovereign yields display a low correlation (0.17 and insignificant). However, if they face a common time-varying process for the world interest rate the co-movement between their sovereign yields increases significantly: the correlation is now 0.40 and significant. This is close to the observed mean correlation observed in the data $(0.53)$.

The rest of the paper is organized as follows. Section 2 briefly reviews the related literature. Section 3 describes the model and defines the equilibrium. Section 4 discusses the numerical solution and the calibration. Section 5 presents the results and section 6 concludes. An appendix presents details about our data as well as additional results and robustness exercises.

\section{Related Literature}

There is ample evidence that movements in the international risk-free rate (usually proxied by the US T-bill rate) have macroeconomic consequences for emerging economies. Neumeyer and Perri (2005) report that real country interest rates in emerging economies are strongly countercyclical and tend to lead the cycle. They also find that exogenous interest rate shocks can account for up to 50 percent of the volatility of output in Argentina. Uribe and Yue (2006) find a strong relationship between the world interest rate, the country spread and emerging market fundamentals. In particular, they show that US interest rate shocks and country spread shocks can explain the large movements seen in the aggregate activity of emerging economies. García-Cicco, Pancrazi and Uribe (2010) also find that the country spread shock is one of the most important drivers of emerging economies business cycles. All these papers take the country spread as an exogenous variable with a time-invariant volatil- 
ity, while our work endogenizes both the level and the time-varying volatility of the spread (as a result of default incentives on the part of the sovereign). ${ }^{5}$ There are also a number of empirical papers that include U.S. monetary policy variables (including interest rates) as determinants of sovereign spreads. Arora and Cerisola (2001) explore the empirical determinants of sovereign spreads using data from 11 emerging economies with special emphasis on US monetary policy and using controls typical in the literature. Like us, they find that the level of spreads is increasing in the level of the interest rate as well as a proxy of volatility. ${ }^{6}$ Foley-Fisher and Guimaraes (2013), using a different methodology (identification through heteroskedasticity), also find that an unexpected increase in US inflation-indexed bond yields increases sovereign spreads: a one-percent increase in world interest rates raises sovereign spreads by roughly 0.8 to 1 percent. $^{7}$ As mentioned above, our model-based findings are in line with the empirical evidence from these two studies.

Fernández-Villaverde et al. (2011) study the impact of exogenous time-varying volatility on the macroeconomic dynamics of a small open economy. They examine the effects on the business cycles of Argentina, Ecuador, Venezuela, and Brazil. We follow their approach to modeling the stochastic behavior of the world interest rate, while departing from their approach to modeling the country spread: as already noted, our model is one of endogenous spreads. Then, we explore the mechanism by which world interest rate uncertainty affects the country spreads and default risk in emerging economies. We see our work as complementary to theirs. Guimaraes (2011) highlights the importance of shocks to the level of world interest rates in a theoretical sovereign default model. His work differs from ours in that it does not consider time variation in the volatility of the world interest rate and does not carry out a quantitative evaluation of the model.

Our paper builds on the quantitative literature on sovereign defaults (following Eaton

\footnotetext{
${ }^{5}$ In a recent study, Reyes-Heroles and Tenorio (2017) document the existence of two regimes in the volatility of interest rates at which emerging economies borrow and show that these regimes are closely related to the occurrence of sudden stops in these economies.

${ }^{6}$ Unlike us, Arora and Cerisola (2001) use the federal funds rate as their measure of interest rate and their volatility proxy is constructed from the estimated values of the conditional standard error from an ARCH model for the difference between the three-month U.S. treasury bill yield and the federal funds rate. Despite these differences our findings are similar to their empirical results.

${ }^{7}$ Longstaff, Pan, Pedersen and Singleton (2011) and Fender, Hayo and Neuenkirch (2012) also include a measure of US interest rates in their study of the determinants of sovereign CDS data.
} 
and Gersovitz, 1981, Aguiar and Gopinath, 2006, and Arellano, 2008). Lizarazo (2013) explores how risk aversion on the part of international lenders influences debt and default dynamics of the borrowing country and therefore how the risk premium affects sovereign spreads. Verdelhan and Borri (2010) also explore the role of time-varying risk aversion of lenders in a model with many small open economies that have endowments which are partially correlated with the lender's endowment process. They also find that risk aversion plays an important role in determining spreads and borrowing levels. Building on these two papers, we incorporate risk aversion in our modeling of foreign lenders.

Within the sovereign debt literature, our paper is particularly related to two recent studies. Seoane (2019) studies how changes in aggregate income volatility affect sovereign spreads of Greece, Italy, Portugal, and Spain. He extends the model in Arellano (2008) to include time-varying volatility of the income process which generates substantial variability in spreads. Our work complements his: we keep the income process with a time-invariant volatility and introduce time-varying volatility in the world interest rate process. The second paper is the one by Pouzo and Presno (2016). They study the problem of a small open economy that can default on its obligations in the presence of model uncertainty. In their work, lenders fear that the probability model of the underlying state of the borrowing economy is misspecified and hence may demand higher returns on their investments. Even though we tackle a different type of uncertainty (i.e. time-varying volatility of the world interest rate) the results are consistent: more uncertainty leads to higher and more volatile spreads. ${ }^{8}$

Finally, our paper is also related to the literature on uncertainty shocks in macroeconomic models. ${ }^{9}$ For instance, Justiniano and Primiceri (2008) and Bloom (2009) study the effect of changes in the volatility of technology shocks in general equilibrium models for closed economies. Justiniano and Primiceri (2008) study the changes in volatility in postwar US data by estimating a large-scale dynamic stochastic general equilibrium model allowing for time variation in the structural innovations. They find that shocks specific to investment are mostly responsible for the observed "great moderation." Bloom (2009), on the other hand,

\footnotetext{
${ }^{8}$ Another study in the sovereign debt literature that deals with time-varying volatility is Gu and Stangebye (2017). They study costly information acquisition in a model of defaultable debt and show how this can create time-varying volatility in the spread.

${ }^{9}$ Fernández-Villaverde and Rubio-Ramírez (2013) and Bloom (2014) provide thorough accounts of the growing literature dealing with uncertainty shocks and time-varying volatility in macroeconomics.
} 
shows that uncertainty shocks can generate short sharp recessions and recoveries.

\section{Model}

We consider a small open economy populated by a continuum of households. The economy trades long-duration non-state-contingent bonds with a mass of competitive foreign lenders and has no commitment to repaying its debts. The world interest rate (which matters for bond prices) is time-varying. Time is discrete and goes on forever: $t=0,1,2, \ldots$

\subsection{Domestic Economy}

There is a single tradable good. As is standard in the sovereign default literature, the economy receives a stochastic endowment stream of this good $y_{t}$, where

$$
\log \left(y_{t}\right)=\rho_{y} \log \left(y_{t-1}\right)+\varepsilon_{t}^{y}
$$

with $\left|\rho_{y}\right|<1$, and $\varepsilon_{t}^{y} \sim N\left(0, \sigma_{\varepsilon}^{2}\right)$. The government's objective is to maximize the expected life-time utility of the representative agent in the economy, namely

$$
\mathbb{E}_{0} \sum_{t=0}^{\infty} \beta^{t} u\left(c_{t}\right)
$$

where $\mathbb{E}$ denotes the expectation operator, $c_{t}$ is consumption, $\beta \in(0,1)$ denotes the subjective discount factor, and the $u(\cdot)$ is a period utility function which satisfies $u^{\prime}>0$, $u^{\prime \prime}<0$.

Each period, the government makes two decisions. First, it decides whether to default. Second, it chooses the number of bonds that it purchases or issues in the current period.

The government has access to an international financial market where it trades longduration non-contingent bonds with competitive foreign investors at a price $q_{t}$. As in Hatchondo and Martinez (2009), we assume that a bond issued in period $t$ promises an infinite stream of coupons, which decrease at a constant rate $\delta$. In particular, a bond issued in period $t$ promises to pay one unit of the good in period $t+1$ and $(1-\delta)^{s-1}$ units in period $t+s$, with $s \geq 2$. Let $b_{t}\left(b_{t+1}\right)$ denote the number of outstanding coupon claims at the 
beginning of the current (next) period. A positive value of $b_{t}$ implies that the government was a net issuer of bonds in the past. The number of bonds issued by the government is given by $\left[b_{t+1}-(1-\delta) b_{t}\right]$. The resource constraint for the repayment case is then given by:

$$
c_{t}+b_{t}=y_{t}+q_{t}\left[b_{t+1}-(1-\delta) b_{t}\right]
$$

If the government declares a default, it is excluded from financial markets and remains in financial autarky for a stochastic number of periods. While the government is in default, it cannot issue debt and domestic aggregate income is reduced by $\phi(y)$. As in Arellano (2008) and Chatterjee and Eyigungor (2012), we assume that it is proportionally more costly to default in good times $(\phi(y) / y$ is increasing in $y) .{ }^{10}$ Following most studies of sovereign default, the income-cost of defaulting is not a function of the size of the default. ${ }^{11}$ Thus, when the government defaults, it does so on all current and future debt obligations. As argued in Hatchondo, Martinez and Sosa-Padilla (2016), this is consistent with the behavior of defaulting countries. ${ }^{12}$ Following previous studies, we also assume that the recovery rate for debt in default is zero. The resource constraint for the default case is given by:

$$
c_{t}=y_{t}-\phi\left(y_{t}\right)
$$

\section{$3.2 \quad$ Foreign Lenders}

Foreign creditors are risk averse and their stochastic discount factor is given by:

$$
m_{t, t+1}=e^{-r_{t+1}-\kappa_{y}\left(\varepsilon_{t+1}^{y}+0.5 \kappa_{y} \sigma_{\varepsilon}^{2}\right)}, \quad \text { with } \quad \kappa_{y} \geq 0 .
$$

\footnotetext{
${ }^{10}$ Arellano (2008) and Chatterjee and Eyigungor (2012) show that this property is important in accounting for the dynamics of the sovereign debt interest rate spread. Mendoza and Yue (2012) show that this property of the cost of defaulting arises endogenously in a setup in which defaults affect the ability of local firms to acquire a foreign intermediate input good.

${ }^{11}$ See Sosa-Padilla (2018) for a model of endogenous default costs, where the output cost of default is a function of the amount of debt that is defaulted upon.

${ }^{12}$ Sovereign debt contracts often contain acceleration and cross-default clauses. These clauses imply that after a default event, future debt obligations become current. The type of acceleration clauses depend on the details of each bond contract and on the jurisdiction under which the bond was issued (see IMF, 2002). For instance, in some cases it is necessary that creditors holding a minimum percentage of the value of the bond issue request their debt to be accelerated for their future claims to become due and payable. In other cases, no such qualified majority is needed.
} 
This formulation introduces a positive risk premium because bond payoffs are more valuable to lenders in states in which the government is more likely to default (i.e., in states in which income shocks in the domestic economy, $\varepsilon^{y}$, are low). Here, $r$ is the time-varying world interest rate, and $\kappa_{y}$ is the parameter governing the magnitude of the risk premium. A higher value of $\kappa_{y}$ can be seen as capturing how correlated the small open economy is with respect to the lenders' income process, or alternatively, the degree of diversification in foreign lenders' portfolios. ${ }^{13}$

Bonds are priced in a competitive market inhabited by a large number of identical lenders, which implies that bond prices are pinned down by a zero expected profit condition. The price per bond is then given by:

$$
q_{t}=\mathbb{E}_{t}\left\{m_{t, t+1}\left(1-d_{t+1}\right)\left[1+(1-\delta) q_{t+1}\right]\right\}
$$

where $d_{t+1}$ and $q_{t+1}$ represent the government's default decision and equilibrium bond price in period $t+1$, respectively.

\subsection{Law of Motion for the World Interest Rate}

Following Fernández-Villaverde et al. (2011) we specify the international risk-free rate faced by investors as:

$$
r_{t}=\bar{r}+\varepsilon_{r, t}
$$

where $\bar{r}$ is the mean of world risk-free real rate, and $\varepsilon_{r, t}$ represents deviations from this mean. In particular, we assume the following $\operatorname{AR}(1)$ behavior for $\varepsilon_{r, t}$ :

$$
\varepsilon_{r, t}=\rho_{r} \varepsilon_{r, t-1}+e^{\sigma_{r, t}} u_{r, t}
$$

\footnotetext{
${ }^{13}$ This modeling of risk-averse foreign lenders follows Vasicek (1977) and has been used recently in the sovereign debt literature (Arellano and Ramanarayanan, 2012, Bianchi and Sosa-Padilla, 2020, etc.). The functional form for the lenders' stochastic discount factor (SDF) makes it explicit that the variance of the domestic income matters, but it is less clear that the variance of $r_{t}$ also affects the SDF through the level of $r_{t}$ (see equation 8). Since $r_{t}$ is time-varying its volatility will induce additional time variation in the SDF. The appendix shows that our results are robust to using a richer specification for (5) (one that explicitly includes the variance of $r_{t}$ ).
} 
where $u_{r, t}$ is a normally distributed shock with mean zero and unit variance. The crucial ingredient in this stochastic process is that the standard deviation $\left(\sigma_{r, t}\right)$ is not constant but time-varying, and itself follows another (independent) AR(1) process:

$$
\sigma_{r, t}=\left(1-\rho_{\sigma_{r}}\right) \bar{\sigma}_{r}+\rho_{\sigma_{r}} \sigma_{r, t-1}+\eta_{r} u_{\sigma_{r}, t}
$$

where $u_{\sigma_{r}, t}$ is a normally distributed shock with mean zero and unit variance. We further assume that $u_{r, t}$ and $u_{\sigma_{r}, t}$ are independent of each other. The parameters $\overline{\sigma_{r}}$ and $\eta_{r}$ measure the degree of mean volatility and stochastic volatility in the international risk free rate. A high $\overline{\sigma_{r}}$ corresponds to a high mean volatility and a high $\eta_{r}$ corresponds to a high degree of stochastic volatility in the international risk free rate.

\subsection{Timing}

The timing of events, for a government that is not excluded from financial markets, is as follows. The government starts with an initial bond position $b_{t}$ and observes the realizations of the income level $\left(y_{t}\right)$, the world interest rate level $\left(r_{t}\right)$ and the interest rate volatility $\left(\sigma_{r, t}\right)$, and then decides whether to repay its outstanding debt. If it decides to repay, it chooses $b_{t+1}$ subject to the resource constraint, taking the bond price schedule $q_{t}\left(b_{t+1} ; y_{t}, r_{t}, \sigma_{r, t}\right)$ as given. Finally, consumption takes place.

On the other hand, if the government decides to default it gets excluded from financial markets and suffers a direct income loss. In case of default, there is no other decision to be made as the level of consumption equals the (reduced) income level. The government will re-access financial markets in the following period with probability $\mu$ (and it will remain excluded from financial markets with probability $1-\mu$ ).

\subsection{Recursive Equilibrium}

We now turn to recursive notation, where primes denote next-period value of the variables. Let $\mathbf{s}=\left\{y, r, \sigma_{r}\right\}$ denote the aggregate exogenous state. Given a number of outstanding coupon claims at the beginning of the next period $b^{\prime}$ and a realization of $\mathbf{s}$, the price of a bond satisfies: 


$$
q\left(b^{\prime}, \mathbf{s}\right)=\mathbb{E}_{\mathbf{s}^{\prime} \mid \mathbf{s}}\left\{m\left(\mathbf{s}^{\prime}, \mathbf{s}\right)\left(1-d^{\prime}\right)\left[1+(1-\delta) q\left(b^{\prime \prime}, \mathbf{s}^{\prime}\right)\right]\right\}
$$

where $d^{\prime}$ is the next-period default decision, and $b^{\prime \prime}$ is the next-period debt choice. The optimal default decision is taken as:

$$
v^{0}(b ; \mathbf{s})=\max _{d \in\{0,1\}}\left\{(1-d) v^{c}(b ; \mathbf{s})+d v^{d}(\mathbf{s})\right\}
$$

where $d$ equals $1(0)$ if the government chooses to (not to) default. Under no-default, the government solves the following problem:

$$
v^{c}(b ; \mathbf{s})=\max _{b^{\prime}}\left\{u\left(y+q\left(b^{\prime} ; \mathbf{s}\right)\left(b^{\prime}-(1-\delta) b\right)-b\right)+\beta \mathbb{E}_{\mathbf{s}^{\prime} \mid \mathbf{s}}\left[v^{0}\left(b^{\prime} ; \mathbf{s}^{\prime}\right)\right]\right\}
$$

Under default, the value function is given by:

$$
v^{d}(\mathbf{s})=u(y-\phi(y))+\beta \mathbb{E}_{\mathbf{s}^{\prime} \mid \mathbf{s}}\left[\mu v^{0}\left(0 ; \mathbf{s}^{\prime}\right)+(1-\mu) v^{d}\left(\mathbf{s}^{\prime}\right)\right]
$$

where, in order to keep the environment as simple as possible, we assume that when the government gains re-access to financial markets it does so with no debt obligations (i.e. it gets a "fresh start"). ${ }^{14}$ Next, we define the recursive equilibrium of this economy.

Definition 1. The recursive equilibrium for this economy is characterized by

1. a set of value functions $v^{0}, v^{c}$, and $v^{d}$,

2. a default policy rule $d$ and a borrowing policy rule $b^{\prime}$,

3. a bond price function $q$,

such that:

(a) given the default and borrowing policy functions, $v^{0}, v^{c}$, and $v^{d}$ satisfy equations (11) - (13) when the government can trade bonds at q;

\footnotetext{
${ }^{14}$ For studies with positive recovery rates and renegotiation between sovereigns and lenders, see for example Yue (2010), D'Erasmo (2011), and Hatchondo et al. (2016).
} 
(b) given the default and borrowing policy functions, the bond price function $q$ is given by equation (10);

(c) the default and borrowing policy functions $d$ and $b^{\prime}$ solve the dynamic programming problem defined by equations (11) - (13) when the government can trade bonds at $q$.

\section{Numerical Solution}

We solve the model numerically using value function iteration on a discrete state space. ${ }^{15}$ We focus on Markov-perfect equilibria. We solve for the equilibrium of the finite-horizon version of our economy, and we increase the number of periods of the finite-horizon economy until value functions and bond prices for the first and second periods of this economy are sufficiently close. We then use the first-period equilibrium objects as the infinite-horizon economy equilibrium objects.

The functional form for the period utility is:

$$
u(c)=\frac{c^{1-\gamma}}{1-\gamma}
$$

where $\gamma$ is the coefficient of relative risk aversion. As in Chatterjee and Eyigungor (2012), we assume a quadratic loss function for income during a default episode:

$$
\phi(y)=\max \left\{0, d_{0} y+d_{1} y^{2}\right\}
$$

As explained by Chatterjee and Eyigungor (2012), this functional form for the income loss $\phi(y)$ is flexible enough to accommodate many cases. If $d_{0}>0$ and $d_{1}=0$, then the cost is proportional to income; if $d_{0}=0$ and $d_{1}>0$, then the cost increases more than proportionately with income; if $d_{0}<0$ and $d_{1}>0$, then the cost is zero in a region $\left(0<y<-d_{0} / d_{1}\right)$ and then increases faster than income (for $\left.y>-d_{0} / d_{1}\right)$. This last case is similar to Arellano (2008)'s cost-of-default function.

\footnotetext{
${ }^{15}$ We use Tauchen (1986)'s method to discretize the income shock and Rouwenhorst's method to discretize the interest rate level shock and the interest rate volatility shock (as suggested by Kopecky and Suen, 2010). The results in section 5 are obtained using the following grids: 200 points for $b, 35$ points for $y, 7$ points for $r$, and 7 points for $\sigma_{r}$. Our results are robust to increasing the grid sizes by $50 \%$ in each dimension at a time, and in all dimensions simultaneously (see Johri, Khan and Sosa-Padilla, 2020 Appendix E).
} 
Table 1: Parameters of Full Model Economy

\begin{tabular}{lccl}
\hline Household risk aversion & $\gamma$ & 2 & Standard value \\
Household's discount factor & $\beta$ & 0.96 & Standard value \\
Mean int'l risk-free rate & $\bar{r}$ & 0.01 & Standard value \\
Income autocorrelation coefficient & $\rho_{y}$ & 0.933 & Estimated \\
Std. dev. of income innovations & $\sigma_{\varepsilon}$ & 0.027 & Estimated \\
Probability of re-entry & $\mu$ & 0.0385 & Chatterjee and Eyigungor $(2012)$ \\
Coupon decay rate & $\delta$ & 0.0742 & Average debt duration \\
\hline Lenders' risk aversion & $\kappa_{y}$ & 8.75 & Calibrated to fit targets \\
Default cost parameter & $d_{0}$ & -0.47 & Calibrated to fit targets \\
Default cost parameter & $d_{1}$ & 0.60 & Calibrated to fit targets \\
\hline
\end{tabular}

\subsection{Calibration}

We define as "full model" the one in which all the shocks are present. This full model is calibrated to a quarterly frequency using data from a group of 13 emerging economies for the years 1994-2008. ${ }^{16}$ These countries and time frame are the union of those used in FoleyFisher and Guimaraes (2013) and Arora and Cerisola (2001) since we intend to compare the predictions of our model to these empirical studies.

Table 1 has the parameter values.

We estimate equation (1) using quarterly real GDP data. The re-entry probability $\mu$ is set to 0.0385 according to Chatterjee and Eyigungor (2012). ${ }^{17}$

We assume the representative agent in economy has a coefficient of relative risk aversion $\gamma$ of 2 , the typical value in the literature. The average risk-free rate and the domestic discount factor $(\bar{r}=0.01$ and $\beta=0.96)$ are standard in quantitative business cycle and sovereign default studies. We set $\delta=7.42 \%$. This value implies a risk-free duration for the sovereign debt of 3 years, which is close to the average duration found in previous literature. ${ }^{18}$

\footnotetext{
${ }^{16} \mathrm{As}$ is common in the sovereign default literature, we focus on time series that exclude default crises. The appendix has details of the country coverage.

${ }^{17}$ This value for $\mu$ implies an average financial exclusion of 6.5 years. Gelos, Sahay and Sandleris (2011) report an average exclusion of 4.7 years for emerging economies. Uribe and Schmitt-Grohé (2017) find an average exclusion of 8 years.

${ }^{18}$ We use the risk-free Macaulay definition of duration that, with the coupon structure in this paper, is given by $D=(1+\bar{r}) /(\delta+\bar{r})$. Focusing on Mexico (an important emerging economy which is in our dataset), Bianchi and Sosa-Padilla (2020) also target a debt duration of 3 years. Using a sample of 27 emerging economies, Cruces, Buscaglia and Alonso (2002) find an average duration of 4.77 years, with a standard deviation of 1.52 years.
} 
Table 2: Estimates of the World Interest Rate Process

\begin{tabular}{lcc}
\hline Autocorrelation risk-free rate & $\rho_{r}$ & 0.908 \\
Mean volatility of int'l risk-free rate & $\overline{\sigma_{r}}$ & -6.2869 \\
Autocorrelation interest vol. shock & $\rho_{\sigma_{r}}$ & 0.8742 \\
Stochastic vol. of int'l risk-free rate & $\eta_{r}$ & 0.2632 \\
\hline
\end{tabular}

We are left with three parameters to assign values to: the parameter controlling the risk premium, $\kappa_{y}$, and the coefficients of the default cost function, $d_{0}$ and $d_{1}$. We calibrate these three parameters to the median values of the debt-to-income ratio (44\%), the sovereign spread (4.1\%), and the standard deviation of the spread (1.9\%). All the data counterparts are the medians observed in our panel of emerging economies.

Table 2 presents the parameterization of the stochastic processes that govern the behavior of the world interest rate. We estimate equations (8) and (9) using data on the real international risk free rate for the period 1990 - 2017. ${ }^{19}$ We obtain this rate by subtracting expected inflation from the quarterly US T-bill rate. Following Neumeyer and Perri (2005) and Fernández-Villaverde et al. (2011), we compute expected inflation as the average of the US CPI inflation in the current quarter and in the 3 preceding quarters. Parameter values in Table 2 correspond to the median of the posterior estimates. These posterior estimates imply annualized average standard deviations for the risk-free interest rate of 74 basis points (with only mean volatility) and 97 basis points with both mean and stochastic volatility.

\subsection{Model fit}

In order to compute the sovereign spread implicit in a bond price, we first compute the yield $r^{b}$ an investor would earn if it holds the bond to maturity (forever in the case of our bonds) and no default is ever declared. This yield $r^{b}$ satisfies

$$
q_{t}=\frac{1}{1+r^{b}}+\frac{1-\delta}{\left(1+r^{b}\right)^{2}}+\frac{(1-\delta)^{2}}{\left(1+r^{b}\right)^{3}}+\ldots
$$

\footnotetext{
${ }^{19}$ We use the stochvol $\mathrm{R}$ package, which implements an efficient algorithm for Bayesian estimation of stochastic volatility models via MCMC methods. See Kastner (2016) for more details on the estimation procedure.
} 
Table 3: Model fit - targeted and non-targeted moments

\begin{tabular}{lcc}
\hline & Data & Full Model \\
Debt/y (in \%) & 44 & 44 \\
Spread (in \%) & 4.1 & 4.1 \\
SD (Spread) (in \%) & 1.9 & 2.1 \\
\hline $\operatorname{sd}(c) / \operatorname{sd}(y)$ & 1.1 & 1.6 \\
$\operatorname{corr}(c, y)$ & 0.8 & 1.0 \\
$\operatorname{corr}($ Spread,$y)$ & -0.5 & -0.8 \\
\hline
\end{tabular}

Note: the standard deviation of a variable $x$ is denoted by $s d(x)$ and the correlation between two variables $x$ and $z$ is denoted by $\operatorname{corr}(x, z)$. We detrend the log of income $(y)$ and consumption $(c)$ using the HP filter, with a smoothing parameter of 1,600. We report deviations from trend.

We then compute a similar constant yield, $r^{f}$, for an otherwise identical but default-free bond. ${ }^{20}$ The annualized sovereign spread is computed as $4\left(r^{b}-r^{f}\right)$.

Having calibrated the model, we first verify its ability to reproduce basic features of emerging economy business cycles and that the targets used in calibration are closely approximated. Table 3 reports several key moments in the data and in our simulations of the full model. ${ }^{21}$

The moments reported in Table 3 are chosen to illustrate the ability of the full model to replicate distinctive business cycle properties of economies with sovereign risk. This table shows that the full model approximates well the moments used as targets (the debt-toincome ratio, and the level and volatility of the sovereign spread) and it is broadly consistent

\footnotetext{
${ }^{20}$ The price of a default-free bond (that is otherwise identical to the bond issued by the small open economy) is given by the following functional equation:$$
q^{D F}(\mathbf{s})=\mathbb{E}_{\mathbf{s}^{\prime} \mid \mathbf{s}}\left\{m\left(\mathbf{s}^{\prime}, \mathbf{s}\right)\left[1+(1-\delta) q^{D F}\left(\mathbf{s}^{\prime}\right)\right]\right\} .
$$

Therefore, the default-free yield $r^{f}$, is the constant yield-to-maturity that satisfies:

$$
q_{t}^{D F}=\frac{1}{1+r^{f}}+\frac{1-\delta}{\left(1+r^{f}\right)^{2}}+\frac{(1-\delta)^{2}}{\left(1+r^{f}\right)^{3}}+\ldots
$$

${ }^{21}$ As in previous studies, we report results for pre-default simulation samples. We simulate the model for 500 samples of 1,500 periods each. We then discard the initial 1,000 periods of each sample as a burn-in and from the remaining data we extract 500 samples of 26 consecutive years before a default. 26 years (or 104 quarters), is the length of the time series for the US T-bill rate used to estimate the process of the world interest rate.
} 
with non-targeted moments in the data: consumption is procyclical and more volatile than income, and the sovereign spread is also countercyclical.

\section{Results}

In this section, we discuss the implications of introducing time variation in both the level and the volatility of the world interest rate. We begin by showing the response of spreads to a rise in the world interest rate which is substantial on average and highly state-contingent, depending on income, debt levels, and the volatility state. Next, we discuss how borrowing decisions are impacted by the level and volatility of world interest rates. We proceed to show that variability in the world interest rates is a source of international co-movement in borrowing costs. We close this section by comparing the full model to one where the world interest rate is constant, emphasizing the welfare losses associated with interest rate uncertainty.

\subsection{Main result: the effect of changes in the risk-free rate on spreads}

Here we present and discuss the main results of the paper. In particular, we study the response of the sovereign spreads to changes in the world interest rate and highlight how this response is highly state contingent (that is to say, it depends on the actual levels of income, debt and volatility at which these rate movements occur). ${ }^{22}$

Reading equations (5) and (6) we first note that if lenders face a higher $r$, then the lenders' stochastic discount factor $\left(m_{t, t+1}\right)$ and the bond price $(q)$ will mechanically fall (implying higher sovereign yields). On top of this purely mechanical pass-through of higher borrowing costs (from the lenders to the borrower), there will be additional effects due to the equilibrium response of the sovereign.

The higher yields change the default incentives (and therefore sovereign spreads) of the sovereign through two main forces. First, higher borrowing costs imply that more consumption must be sacrificed in order to roll-over existing debt, ceteris paribus, which lowers the

\footnotetext{
${ }^{22}$ Henceforth we refer to 'low' and 'high' values of $r$ and $\sigma_{r}$ to illustrate the state-contingent nature of the effects. Low and high values of $r$ and $\sigma_{r}$ refer to values that are 4 standard deviations below and above mean.
} 


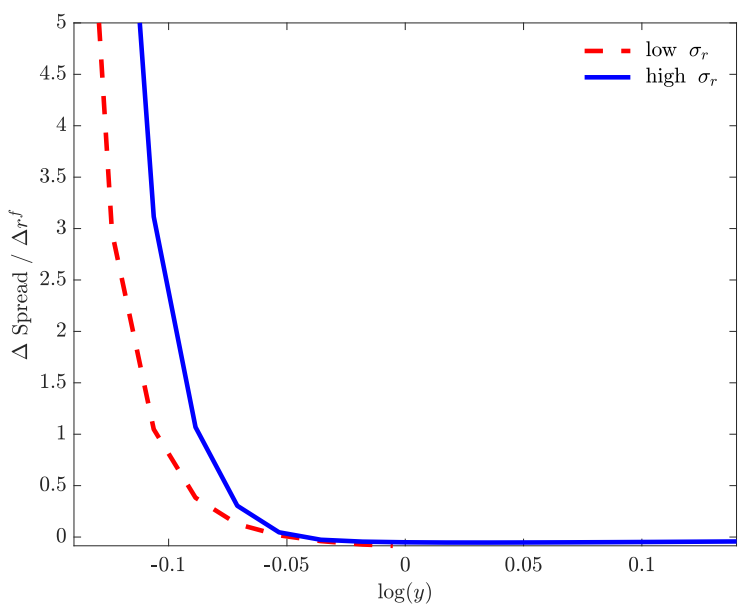

(a) Effect of $\sigma_{r}$

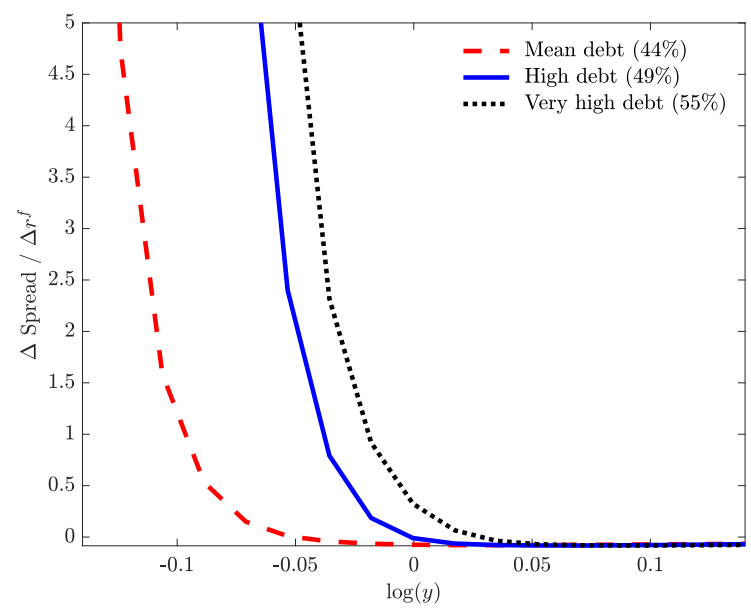

(b) Effect of debt

Figure 1: Spread slopes ( $\Delta$ Spread $/ \Delta r^{f}$ ). The left panel keeps $b^{\prime}$ at its mean and the right panel keeps $\sigma_{r}$ at its mean. This figure is constructed for a $100 \mathrm{bps}$ increase in the world interest rate. In both panels we allow future debt levels to be chosen optimally.

desire to repay. Second, since $r$ follows a persistent process, higher borrowing costs today are likely to remain in place in the near future. This makes the threat of financial exclusion less severe, as the periods in which the sovereign would be unable to borrow would likely be periods of high borrowing costs. Both forces go in the same direction, increasing incentives to default and (ceteris paribus) increasing the spreads.

Figure 1 illustrates the dynamics just described above. It shows how the sovereign spread reacts to changes in the world interest rate as a function of the income level. The first thing to notice is the asymmetric response of the spread along the income dimension: for low income levels the increase in spreads can be very large (with $\frac{\Delta \text { Spread }}{\Delta r^{f}}$ being larger than 3 if income is $10 \%$ below mean) while it is negligible when income is above mean. ${ }^{23}$ The second thing to notice is how the response of spreads depends on the volatility of the world interest rate. Panel (a) of Figure 1 keeps debt at the mean level observed in the simulations and varies $\sigma_{r}$. The solid blue line refers to the high volatility state while the dashed red line to the low volatility state. We find that, other things equal, the impact of changes in the world

\footnotetext{
${ }^{23}$ Notice that the effect can even be slightly negative for high income levels. The rationale is straightforward. The spread is computed as the (annualized) difference between the implied yield of a sovereign bond and the yield on an otherwise identical but default-free bond. The sovereign yield is always increasing in $r$ (making the borrowing costs higher) but so is the default-free yield. At high income levels the latter increases slightly more, which accounts for the small negative effect on spreads.
} 
interest rate on the sovereign spread is larger in high volatility states. Again, this difference is materially important at low income levels and essentially zero above mean income. The third result to highlight is how the effect depends on the debt chosen by the government. Panel (b) of Figure 1 makes it clear that the impact of increases in the world interest rate on spreads are amplified by higher debt levels. For example, if the economy is in a moderate recession (with quarterly income being $5 \%$ below mean) the spread slope is close to zero under the mean debt level but close to 2 if the debt level is only $5 \%$ higher (at $49 \%$ of GDP instead of $44 \%$ ).

Overall, how big is the effect in the model simulations? We focus on reasonable changes in the default-free yield (5-25 bps), keeping $b^{\prime}$ constant (while allowing future levels of debt to vary according to the optimal policy rules), and letting income vary up to 2 standard deviations around its mean value. Within these empirically relevant boundaries, we compute the spread slope $\left(=\frac{\Delta \text { Spread }}{\Delta r^{f}}\right)$ and find that when evaluated at mean volatility it is 1.4 . The impact of volatility on the spread slope is quite substantial - it is 0.8 at the low volatility state and 6.4 at the high volatility state. This highlights the highly state contingent interaction of the level and volatility of the risk-free rate. We conclude that the model is able to produce effects of shocks to the world interest rate on sovereign spreads that are in line with the empirical evidence (a spread slope of roughly 1), as presented in Foley-Fisher and Guimaraes (2013) and Arora and Cerisola (2001). ${ }^{24}$

\subsection{Effect on borrowing decisions}

Figure 2 shows the effect of different levels of the world interest rate on borrowing decisions as reflected in the debt issuance, for two different volatility levels. ${ }^{25}$ It is clear from this figure that the small open economy borrows more when lenders face a low world interest rate compared to when lenders face a high interest rate. The issuance function for the low $r$ level lies consistently above the one for high $r$ level. This pattern can be seen at both

\footnotetext{
${ }^{24}$ The way we compute the spread slope, keeping $b^{\prime}$ constant, is in the spirit of a common empirical strategy in which the spread response is calculated over a window that is short enough that debt is assumed not to immediately react to the interest rate shock. In both the model and empirical exercises, rational agents will naturally price the sovereign bonds anticipating future movements in debt.

${ }^{25}$ The focus on the response of debt issuance in our paper is equivalent to the focus on debt changes in the literature with one-period debt. An equivalent analysis of debt-responses can be found in the Appendix.
} 


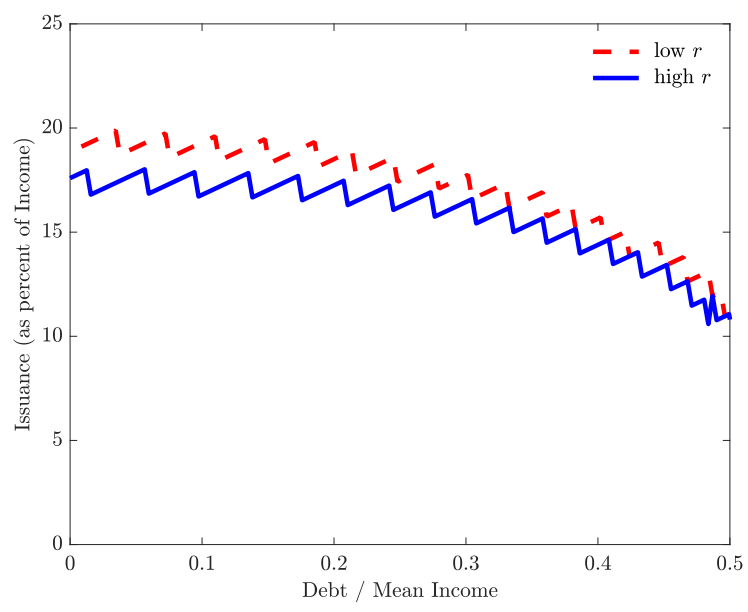

(a) Low $\sigma_{r}$

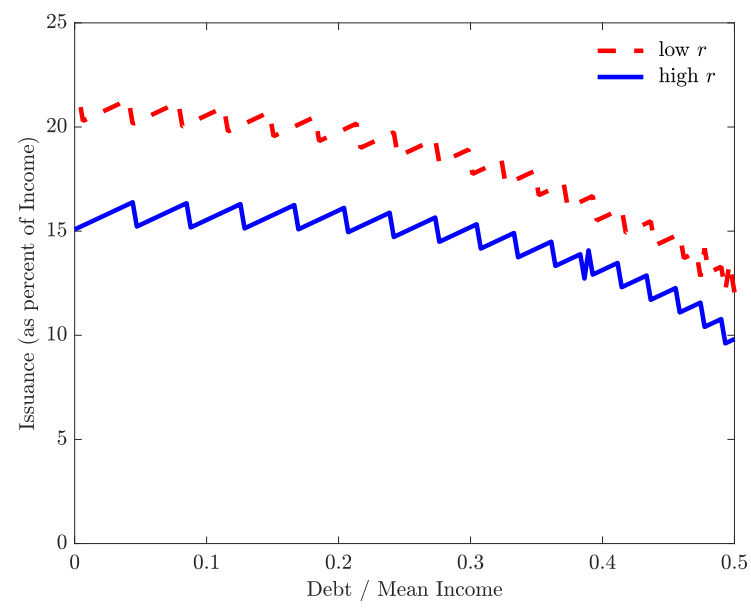

(b) High $\sigma_{r}$

Figure 2: Effect of interest rate on debt issuance. The left panel is for a low level of $\sigma_{r}$ and the right panel is for a high level of $\sigma_{r}$. The solid blue line is for high $r$ while the red dashed line is for low $r$. Both panels are for the mean income level.

low and high volatility levels in panels (a) and (b) respectively, with an increase in volatility magnifying the effect.

These issuance policy function responses to interest rate changes are reflected in the simulations. In order to quantify these responses we follow the previous section and define the issuance slope as $\frac{\Delta \iota}{\Delta r^{f}}$. Holding the volatility state at its mean, we find an issuance slope of -2.7 , on average. The impact of volatility on the issuance slope is also substantial: it is -0.5 at the low volatility state and -5.6 at the high volatility state. This, once again, highlights the impact of the volatility state on model responses.

\subsection{International co-movement in sovereign yields}

Time variation in the world interest rate not only increases the level and volatility of a country's borrowing costs (its sovereign yield) but it can potentially create co-movement between the yields of various countries. To illustrate and quantify this natural implication of our model we perform the following exercise: (i) we draw multiple random (and independent) samples for the income process, (ii) we select the two samples that have the most similar pairwise income correlation to the data ( 0.50 in the simulations and 0.57 in the data), (iii) we feed these sequences of shocks into our full model along with a common (and independent) sequence of shocks to the world interest rate, (iv) we correlate the sovereign yields between 
these two samples (which may be thought of as symbolizing two countries), and (v) finally, we condition the correlation calculation on debt lying 2 percentage points above and below the mean. We find this correlation to be large (0.40) and significant. ${ }^{26}$

We repeat the same process for our 'basic model' where the world interest rate is constant (i.e., we set $u_{r}=u_{\sigma_{r}}=0$ while leaving all other parameters unchanged at their values in the full model) and find a correlation coefficient that is much lower (0.17) and insignificant. ${ }^{27}$ The higher correlation in the full model suggests that global interest rate shocks may play a non-trivial role in generating the observed international co-movement in yields found in our data (a mean correlation between sovereign yields of 0.53 ). ${ }^{28}$

\subsection{Welfare effects}

Having shown that variation in the world interest rate can have state-contingent impacts on the borrowing costs of our "full model" economy, we now wish to quantify the welfare consequences of this variation. To do this we ask: what are the welfare gains of living in the full model as compared to the basic model economy? Figure 3 plots these gains as a function of the income level. The gains are expressed as the constant proportional change in consumption that would leave a consumer indifferent between living in the full model or the basic model where $r$ is constant. We present results for two scenarios. In scenario 1, initial debt is zero while in scenario 2, the economy starts at the mean level of debt.

When initial debt is zero (solid green line), the average (across income levels) welfare gain is $0.01 \%$ of permanent consumption. Note that in this case the welfare gains are decreasing in the income level. For the case with positive initial debt (dashed black line), there are some interesting non-monotonicities at work. At low income levels, the welfare gains are particularly low since default is more likely and the value of defaulting $\left(v^{d}(\mathbf{s})\right)$ under no interest rate uncertainty is not dramatically higher than with uncertainty. However, for intermediate levels of income, the welfare gains are higher because it is precisely in these

\footnotetext{
${ }^{26}$ Not conditioning on debt levels produces a very similar result (a significant correlation of 0.42 ).

${ }^{27}$ There are two possible conceptual ways to decompose the full model - the basic model with no movement in $r$ and the 'intermediate model' which incorporates shocks to the level of $r$ but not to its volatility. A discussion of these models and the corresponding moments can be found in appendix D of Johri et al. (2020).

${ }^{28}$ For this exercise we use quarterly sovereign yields data from Longstaff et al. (2011). The appendix has the details of the data as well as a complete spread correlation matrix.
} 


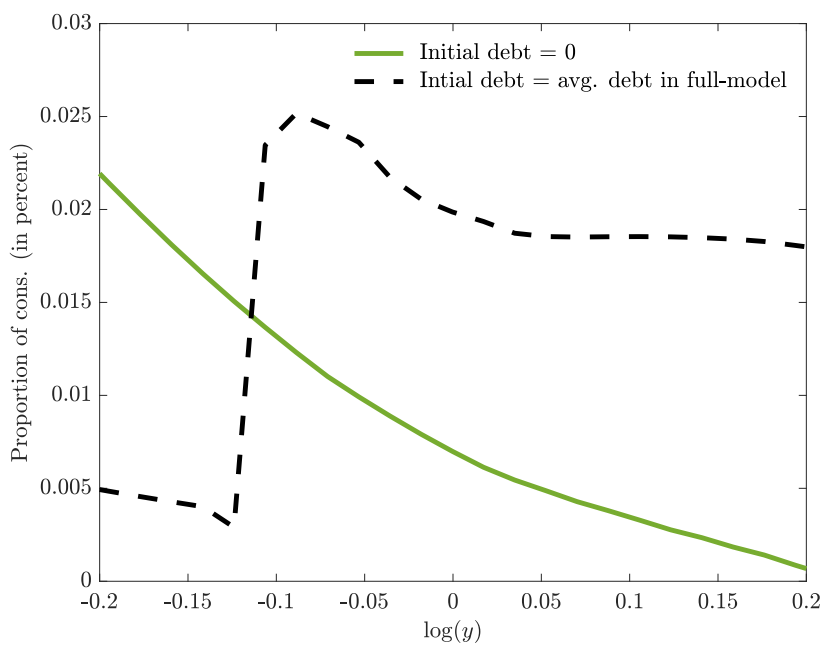

Figure 3: Welfare gains of moving from the full to the basic economy. The initial debt levels are zero in the solid green line, and the mean in the simulations (44\%) in the dashed black line.

states where the basic model implies that the government is able to repay existing debt and also borrow at cheaper rates than in the full model. The average welfare gain of eliminating all uncertainty about the world interest rate in this case (with initial debt equal to the mean level observed in the simulations) is equal to a $0.02 \%$ constant increase in consumption.

\section{Conclusions}

We have introduced time-varying volatility in the world interest rate in a standard sovereign default model with long term debt. The process for the world interest rate includes both mean volatility (i.e., shocks to the level of the interest rate) and stochastic volatility (i.e., shocks to the volatility of the interest rate). Time variation in the world interest rate interacts with default incentives and its effect on borrowing and sovereign spreads is state contingent. We find that the change in spread is on average 1.4 times the increase in the world interest rate when volatility is at its mean. This 'slope' increases to 6.4 when volatility state is high and falls to 0.8 when volatility is low. Not surprisingly, higher debt makes the spread response to the world interest rate stronger.

In our model, the common process for the world interest rate acts as a global factor with the potential to generate international co-movement in sovereign yields. We quantify this by comparing simulations from the basic and full models: independent economies featuring 
uncorrelated borrowing costs under the basic model would produce times series for their sovereign yields that have a positive and significant correlation under the full model (i.e., with a common stochastic process for the world interest rate).

We find positive welfare gains from eliminating uncertainty about the world interest rate and these potentially justify the concerns expressed by policy makers in the face of an increase in uncertainty about the path of the world interest rate.

\section{References}

Aguiar, Mark and Gita Gopinath, "Defaultable debt, interest rates and the current account," Journal of International Economics, 2006, 69, 64-83.

Akıncı, Özge, "Global financial conditions, country spreads and macroeconomic fluctuations in emerging countries," Journal of International Economics, 2013, 91 (2), 358-371.

Arellano, Cristina, "Default Risk and Income Fluctuations in Emerging Economies," American Economic Review, 2008, 98(3), 690-712.

- and Ananth Ramanarayanan, "Default and the maturity structure in sovereign bonds," Journal of Political Economy, 2012, 120 (2), 187-232.

Arora, Vivek and Martin Cerisola, "How does US monetary policy influence sovereign spreads in emerging markets?," IMF Staff papers, 2001, 48 (3), 474-498.

Bianchi, Javier and César Sosa-Padilla, "Reserve Accumulation, Macroeconomic Stabilization, and Sovereign Risk," Technical Report, National Bureau of Economic Research 2020.

Bloom, Nicholas, "The impact of uncertainty shocks," Econometrica, 2009, 77 (3), 623-685.

_ , "Fluctuations in uncertainty," Journal of Economic Perspectives, 2014, 28 (2), 153-76.

Cantor, Richard and Frank Packer, "Determinants and impact of sovereign credit ratings," Economic Policy Review, 1996, 2 (2).

Catão, Luis AV and Rui C Mano, "Default premium," Journal of International Economics, 2017, 107, 91-110.

Chatterjee, Satyajit and Burcu Eyigungor, "Maturity, Indebtedness, and Default Risk," American Economic Review, 2012, 102 (6), 2674-99.

Cruces, Juan José, Marcos Buscaglia, and Joaquín Alonso, "The Term Structure of Country Risk and Valuation in Emerging Markets," 2002. manuscript, Universidad Nacional de La Plata.

D’Erasmo, Pablo, "Government Reputation and Debt Repayment," 2011. Manuscript, Univ. of Maryland. 
Eaton, Jonathan and Mark Gersovitz, "Debt with potential repudiation: theoretical and empirical analysis," Review of Economic Studies, 1981, 48, 289-309.

Edwards, Sebastian, "LDC Foreign Borrowing and Default Risk: An Empirical Investigation, 1976-80," American Economic Review, 1984, 74 (4), 726-734.

Eichengreen, B. and A. Mody, What Explains the Changing Spreads on Emerging Market Debt?, University Of Chicago Press, 2000.

Fender, Ingo, Bernd Hayo, and Matthias Neuenkirch, "Daily pricing of emerging market sovereign CDS before and during the global financial crisis," Journal of Banking E Finance, 2012, 36 (10), 2786-2794.

Fernández-Villaverde, Jesús and Juan F Rubio-Ramírez, "Macroeconomics and Volatility: Data, Models, and Estimation," in "Advances in Economics and Econometrics: Tenth World Congress," Vol. 3 Cambridge University Press 2013, p. 137.

_ , Pablo Guerrón-Quintana, Juan F Rubio-Ramírez, and Martin Uribe, "Risk Matters: The Real Effects of Volatility Shocks," American Economic Review, 2011, 101 (6), 2530-2561.

Foley-Fisher, Nathan and Bernardo Guimaraes, "US real interest rates and default risk in emerging economies," Journal of money, credit and banking, 2013, 45 (5), 967-975.

García-Cicco, Javier, Roberto Pancrazi, and Martín Uribe, "Real Business Cycles in Emerging Countries?," American Economic Review, 2010, 100, 2510-2531.

Gelos, Gaston, Ratna Sahay, and Guido Sandleris, "Sovereign borrowing by developing countries: What determines market access?," Journal of International Economics, 2011, 83 (2), 243-254.

González-Rozada, Martín and Eduardo Levy Yeyati, "Global factors and emerging market spreads," Economic Journal, 2008, 118, 1917-1936.

Gu, Grace Weishi and Zach Stangebye, "The Pricing of Sovereign Risk under Costly Information," 2017. Unpublished manuscript.

Guimaraes, Bernardo, "Sovereign default: which shocks matter?," Review of Economic Dynamics, October 2011, 14 (4), 553-576.

Hatchondo, Juan Carlos and Leonardo Martinez, "Long-duration bonds and sovereign defaults," Journal of International Economics, 2009, 79, 117-125.

_ , _, and César Sosa-Padilla, "Debt dilution and sovereign default risk," Journal of Political Economy, 2016, 124 (5), 1383-1422.

Hilscher, Jens and Yves Nosbusch, "Determinants of sovereign risk: Macroeconomic fundamentals and the pricing of sovereign debt," Review of Finance, 2010, 14 (2), 235-262.

IMF, "The Design and Effectiveness of Collective Action Clauses," 2002.

Johri, Alok, Shahed Khan, and Cesar Sosa-Padilla, "Interest Rate Uncertainty and Sovereign Default Risk," Department of Economics Working Papers 2020-13, McMaster University July 2020. 
Justiniano, Alejandro and Giorgio E Primiceri, "The Time-Varying Volatility of Macroeconomic Fluctuations," The American Economic Review, 2008, 98 (3), 604.

Kastner, Gregor, "Dealing with Stochastic Volatility in Time Series Using the R Package stochvol," Journal of Statistical Software, Articles, 2016, 69 (5), 1-30.

Kopecky, Karen A and Richard MH Suen, "Finite state Markov-chain approximations to highly persistent processes," Review of Economic Dynamics, 2010, 13 (3), 701-714.

Lizarazo, Sandra Valentina, "Default risk and risk averse international investors," Journal of International Economics, 2013, 89 (2), 317-330.

Longstaff, Francis A, Jun Pan, Lasse H Pedersen, and Kenneth J Singleton, "How sovereign is sovereign credit risk?," American Economic Journal: Macroeconomics, 2011, 3 (2), 75-103.

Maltritz, Dominik, "Determinants of sovereign yield spreads in the Eurozone: A Bayesian approach," Journal of International Money and Finance, 2012, 31 (3), 657-672. Financial Stress in the Eurozone.

Mendoza, Enrique and Vivian Yue, "A General Equilibrium Model of Sovereign Default and Business Cycles," Quarterly Journal of Economics, 2012, 127, 889-946.

Neumeyer, Pablo. and Fabrizio Perri, "Business cycles in emerging economies: the role of interest rates," Journal of Monetary Economics, 2005, 52, 345-380.

Pouzo, Demian and Ignacio Presno, "Sovereign default risk and uncertainty premia," American Economic Journal: Macroeconomics, 2016, 8 (3), 230-66.

Rai, Vikram and Lena Suchanek, "The effect of the federal reserve's tapering announcements on emerging markets," Bank of Canada Working Paper, 2014.

Reyes-Heroles, Ricardo and Gabriel Tenorio, "Interest Rate Volatility and Sudden Stops: An Empirical Investigation," 2017.

Seoane, Hernán D, "Time-Varying Volatility, Default, And The Sovereign Risk Premium," International Economic Review, 2019, 60 (1), 283-301.

Sosa-Padilla, César, "Sovereign Defaults and Banking Crises," Journal of Monetary Economics, 2018, 99, 88-105.

Tauchen, George, "Finite state markov-chain approximations to univariate and vector autoregressions," Economics letters, 1986, 20 (2), 177-181.

Uribe, Martin and Stephanie Schmitt-Grohé, Open economy macroeconomics, Princeton University Press, 2017.

Uribe, Martín and Vivian Yue, "Country spreads and emerging countries: Who drives whom?," Journal of International Economics, 2006, 69, 6-36.

Vasicek, O., "An equilibrium characterization of the term structure," Journal of financial economics, 1977, 5 (2), 177-188. 
Verdelhan, Adrien and Nicola Borri, "Sovereign Risk Premia," Technical Report 2010.

Yue, Vivian, "Sovereign default and debt renegotiation," Journal of International Economics, 2010, 80, 176-187. 


\section{OnLine APPENDiX}

\section{A Data}

\section{A.1 Time and country coverage}

In order to have as much comparability with previous studies as possible, we focus on the union of the countries and time periods covered in Foley-Fisher and Guimaraes (2013) and Arora and Cerisola (2001). That amounts to considering data for the period 1994 - 2008 for the following 13 countries: Argentina, Brazil, Bulgaria, Colombia, Indonesia, Korea, Mexico, Panama, Peru, Philippines, Poland, Thailand, and Venezuela.

\section{A.2 World interest rate $(r)$}

We obtain this rate by subtracting expected inflation from the quarterly US T-bill rate. Following Neumeyer and Perri (2005) and Fernández-Villaverde et al. (2011), we compute expected inflation as the average of the US CPI inflation in the current quarter and in the 3 preceding quarters. Both of these time series are obtained from FRED for the period January 1990 - March 2017.

As explained in the main text, we estimate equations (8) and (9) using the stochvol $\mathrm{R}$ package, which implements an efficient algorithm for Bayesian estimation of stochastic volatility models via MCMC methods. Our measure for the 'volatility of the world interest rate' in the regressions is $\exp \left(\sigma_{r, t}\right)$.

The process for $r$ is estimated at a quarterly frequency. We obtain annualized time series by taking the year's mean of both $r_{t}$ and $\sigma_{r, t}$ (but all results hold if we use the median, or the last quarter's value).

\section{A.3 Other variables' definitions}

As is common in studies of emerging economies, we exclude crisis years. Whenever possible, we take the data from the online appendix of Catão and Mano (2017). We also follow them in terms of variable definitions for debt, spreads, and crisis years. Here, we provide a brief description of these variables: ${ }^{29}$

1. Gross Domestic Product (GDP): as reported in IMF's International Financial Statistics. 'GDP growth' is defined as the three-year moving average of the growth rate of GDP.

2. Debt: we focus on external debt. The source is the World Bank's Global Development Finance database.

3. Spreads: the main source for emerging market spreads is JP Morgan's EMBI spreads. The volatility of the country spread is measured as its standard deviation in three-year rolling windows.

4. Crisis years: these are defined as years in which a given country experienced a "credit event." These events are defined as all the years in between the initial default and full (or near full) settlement of arrears as per the Standard and Poor's definition.

\footnotetext{
${ }^{29}$ See Catão and Mano (2017)'s data appendix for further details.
} 


\section{B A different specification for the lender's SDF}

As anticipated in section 3.2 of the main body of the text, we also solve the model allowing for a richer specification of the lenders' stochastic discount factor (SDF). In particular, we allow the lenders' SDF to be affected by $r_{t}$, the innovations to GDP $\left(\varepsilon_{t}^{y}\right)$, the variance of innovations to GDP $\left(\sigma_{\varepsilon}^{2}\right)$, as well as the variance of the innovations to the world interest rate.

The conditional variance of the innovations to the world interest rate is given by:

$$
\operatorname{Var}\left(e^{\sigma_{t+1}} u_{t+1} \mid \sigma_{t}\right)=\left(\tilde{\mu_{\sigma}}\right)^{2} \times \exp \left(2 \eta_{r}\right) \equiv \Omega_{t+1}
$$

where $\tilde{\mu_{\sigma}} \equiv E\left(e^{\sigma_{t+1}} \mid \sigma_{t}\right)$ and $\eta_{r}$ measures the degree of stochastic volatility in the international risk free rate (see section 3.3 in the paper). Therefore, our new SDF is:

$$
m_{t, t+1}=\exp \left(-\left(r_{t+1}+\kappa_{y}\left(\varepsilon_{t+1}^{y}+0.5 \kappa_{y} \sigma_{\varepsilon}^{2}\right)+\kappa_{r} \Omega_{t+1}\right)\right),
$$

where now $\left\{\kappa_{y}, \kappa_{r}\right\}$ control the degree of risk aversion. Since we now have an additional parameter $\left(\kappa_{r}\right)$ we recalibrate our model targeting one additional moment (the unconditional default frequency). The table below shows that the calibration of the model with the 'new SDF' produces almost identical simulated moments. ${ }^{30}$

Table A1: Model fit - targeted and non-targeted moments

\begin{tabular}{lccc}
\hline & Data & Benchmark & New SDF \\
Debt/y (in \%) & 44 & 44 & 43 \\
Spread (in \%) & 4.1 & 4.1 & 4.1 \\
SD (Spread) (in \%) & 1.9 & 2.1 & 2.0 \\
Defaults per 100 years & 1.7 & $1.8^{*}$ & 1.7 \\
\hline $\operatorname{sd}(c) / \operatorname{sd}(y)$ & 1.1 & 1.6 & 1.5 \\
$\operatorname{corr}(c, y)$ & 0.8 & 1.0 & 1.0 \\
$\operatorname{corr}($ Spread, $y)$ & -0.5 & -0.8 & -0.8 \\
\hline
\end{tabular}

Note: table 3's footnote applies here. The default frequency is computed using all simulation periods. The benchmark model's calibration does not target the default frequency $(*)$.

In order to illustrate that all our results are robust to using this richer SDF, we reproduce the spread slope plot (similar to the one in Figure 1). Figure A1 below shows that when we allow for a more general specification for the lender's SDF the response of the sovereign spread to increases in the world interest rate has the same properties as found in section 5.1. Namely, the spread slope is still (i) asymmetric along the income dimension (impact being substantial for low income levels and negligible above mean), (ii) dependent on the volatility state (the impact of changes in the world interest rate is increasing with volatility), and (iii) dependent on the debt chosen by the government (the effect is amplified at higher debt levels)

\footnotetext{
${ }^{30}$ The re-calibration is such that: $\kappa_{y}=9.5$ and $\kappa_{r}=7.5$. All other parameters are unchanged. The default frequency is computed using data for default events from Catão and Mano (2017).
} 


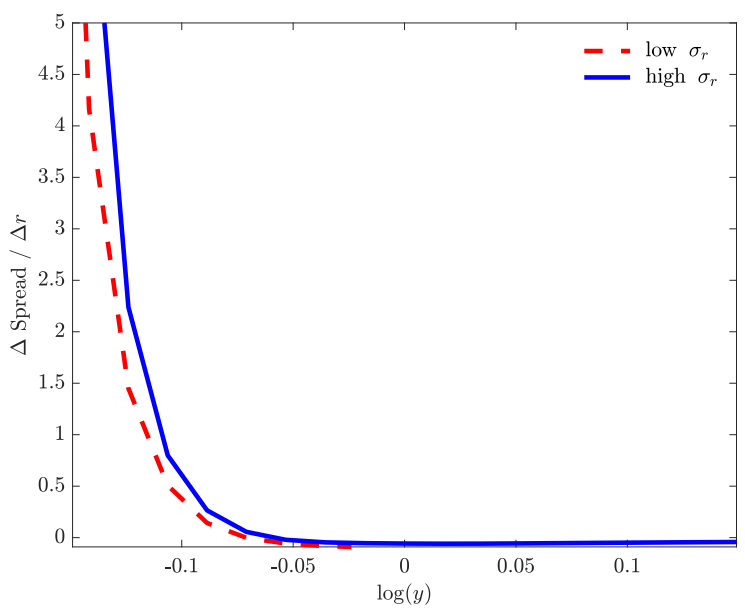

(a) Effect of $\sigma_{r}$

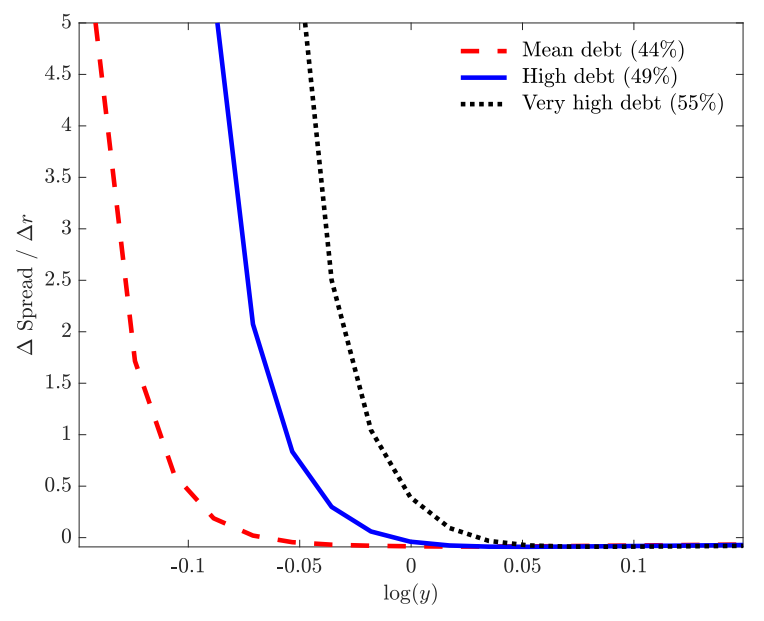

(b) Effect of debt

Figure A1: Effect of changes in the world interest rate on sovereign spreads using a more general SDF. The left panel keeps the debt at its mean and the right panel keeps $\sigma_{r}$ at its mean.

\section{Effect on debt policies}

Figure A2 shows the effect of different levels of the world interest rate on debt policies, for two different volatility levels. It is clear from this figure that the small open economy borrows more when lenders face a low world interest rate compared to when lenders face a high interest rate. The $b^{\prime}$ function for the low $r$ level lies consistently above the one for high $r$ level. Volatility increases this effect.

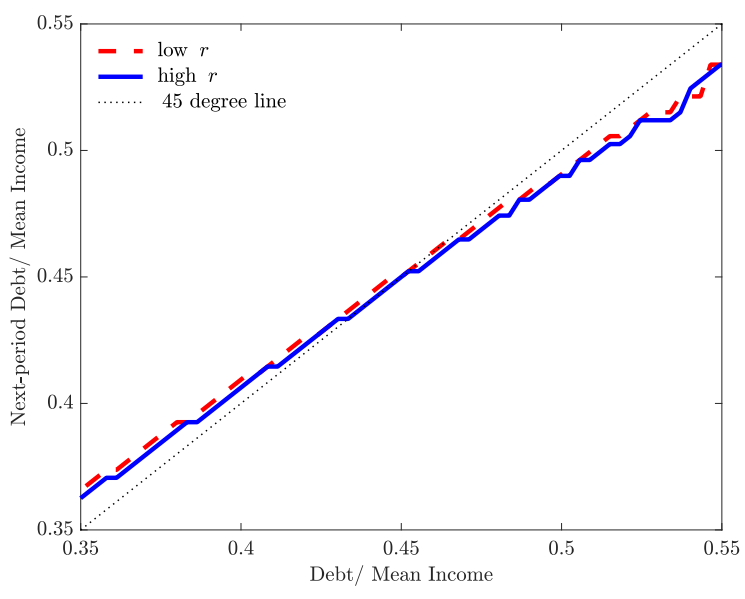

(a) Low $\sigma_{r}$

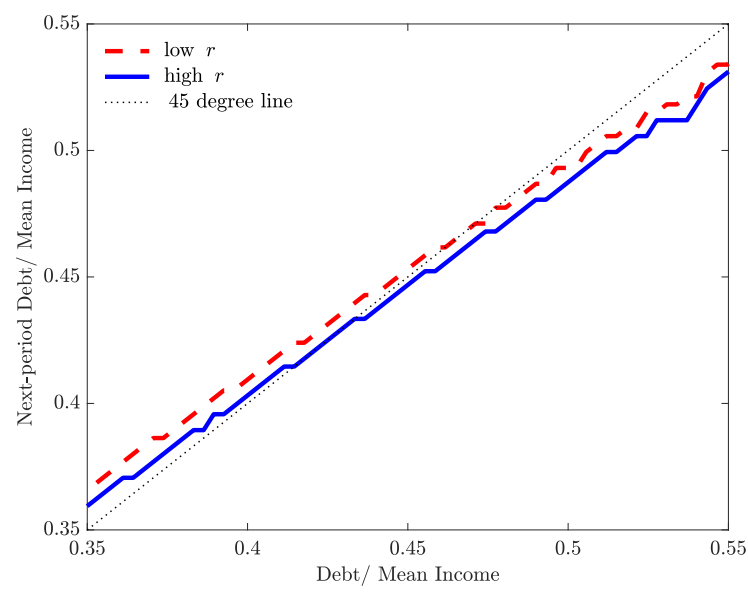

(b) High $\sigma_{r}$

Figure A2: Effect on the debt policy functions. The left panel is for a low level of $\sigma_{r}$ and the right panel is for a high level of $\sigma_{r}$. The solid blue line is for high $r$ while the red dashed line is for low $r$. Both panels are for the mean income level.

Figure A2 also highlights a well known aspect of borrowing decisions in this class of models. At low levels of debt, the policy rules lie above the 45 degree line and at high levels they lie below the 
45 degree line. This occurs because spread-debt menus offered by lenders imply spreads increase in the amount of debt chosen.

\section{Comovement of sovereign yields in the data}

As explained in section 5.3 of the main body of the text, we compute the cross country pairwise correlations in sovereign yields using quarterly data from Longstaff et al. (2011). ${ }^{31}$ Using quarterly data for this particular exercise is more appropriate since low frequency data (like annual data) could mask the true comovement between countries' borrowing costs.

As can be seen in the figure below, every time the pairwise correlation is significant it is also positive, as our model predicts. The mean (median) is $0.53(0.52) .{ }^{32}$

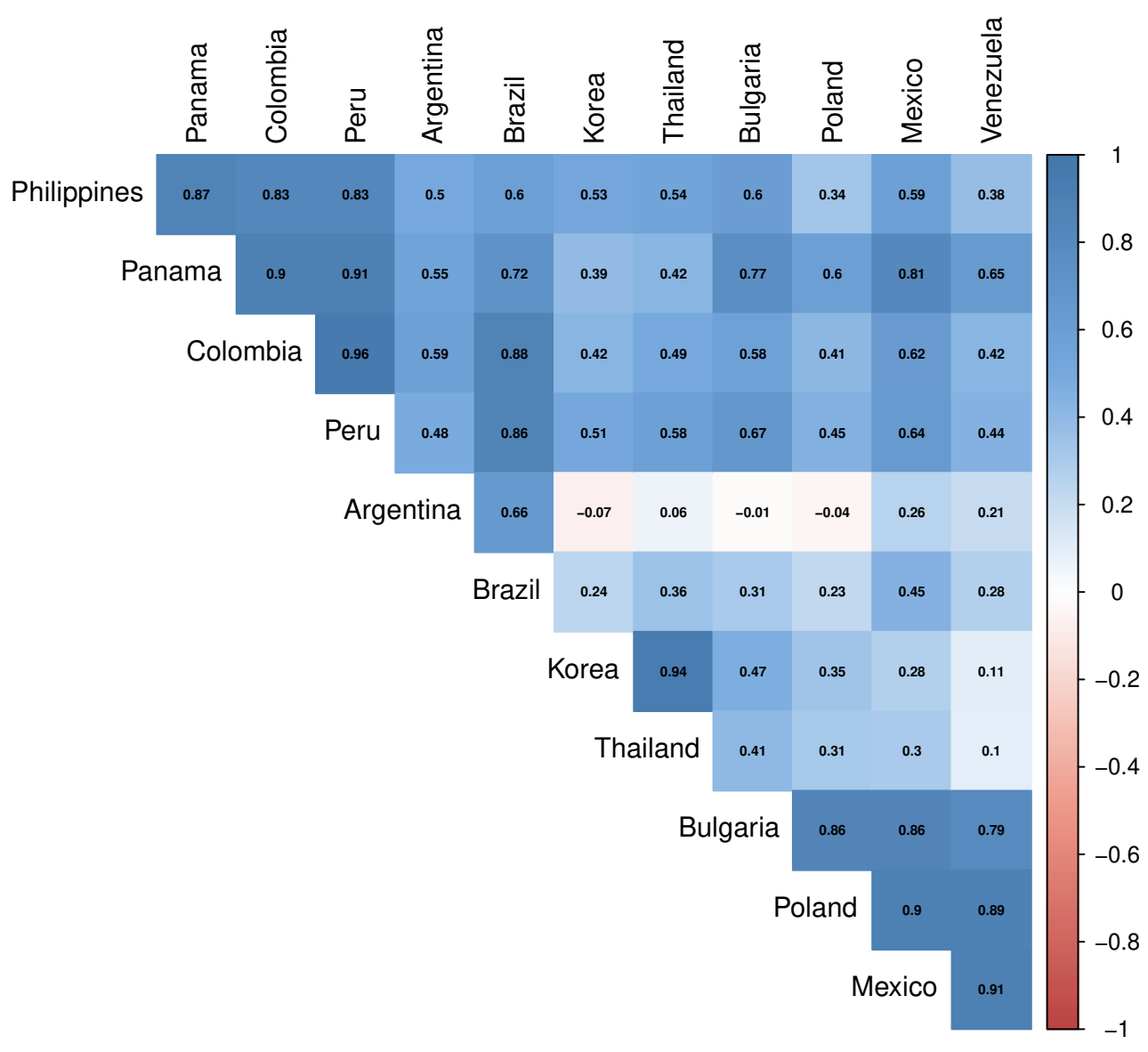

Figure A3: Correlation matrix for sovereign yields. Each cell reports the pairwise correlation.

\footnotetext{
${ }^{31}$ We take Longstaff et al. (2011)'s monthly data and use quarter-end observations to obtain quarterly time-series. Results are similar if we use quarter averages.

${ }^{32}$ Similar results hold if we do this exercise with a larger set of countries. It also holds if we run the calculations on CDS spreads instead of sovereign yields.
} 